\title{
Hepatoprotective Effect of Guava (Psidium guajava L.) Leaf Extracts on Ethanol-Induced Injury on Clone 9 Rat Liver Cells
}

\author{
Hung-Hui Chen ${ }^{1}$, Po-Hua Wu', Diana Lo ${ }^{3}$, Yun-Chieh Pan ${ }^{1}$, Ming-Chang $\mathrm{Wu}^{{ }^{*}}$ \\ ${ }^{1}$ Department of Food Science, National Pingtung University of Science and Technology, Pingtung, Chinese Taipei; ${ }^{2}$ Department of \\ Microbiology, Immunology, and Biophamarceuticals, National Chiayi University, Chiayi, Chinese Taipei; ${ }^{3}$ Department of Tropical \\ Agriculture and International Cooperation, National Pingtung University of Science and Technology, Pingtung, Chinese Taipei. \\ Email: ${ }^{*}$ mowu@mail.npust.edu.tw
}

Received July $31^{\text {st }}, 2011$; revised September $16^{\text {th }}, 2011$; accepted September $23^{\text {rd }}, 2011$.

\begin{abstract}
Guava (Psidium guajava L.), a tropical fruit, belongs to Myrtaceae family. Leaves and fruits of guava have been reported to have an anti-diarrheal, hypoglycemic, lipid lowering, anti-bacterial in addition to antioxidant activities. The aim of this study was to investigate several guava leaf extract cytotoxic effects on healthy clone 9 liver cells and its hepatoprotective effects on ethanol-induced heap-toxicity. It was discovered that when the clone 9 liver cells were treated with guava (Psidium guajava Linn.) extracts for 24 hours, there was no retardation of growth as well as when ethanol and acetone extracts at low concentrations $100 \mu \mathrm{g} / \mathrm{mL}$ and $50 \mu \mathrm{g} / \mathrm{mL}$ were administered however cytototoxic effects were detected at higher concentrations. Water and hot water extracts in concentrations lower than or equal to $500 \mu \mathrm{g} / \mathrm{mL}$ revealed no cytotoxic effects. Injury induction to healthy clone 9 liver cells using 5\% alcohol concentration for 30 minutes revealed the hepatoprotective properties of guava (Psidium guajava Linn.) extracts. This was significant in concentrations of $100 \mu \mathrm{g} / \mathrm{mL}$ or lower for ethanol and all concentrations for hot water extracts. Hot water extracts showed higher hepatoprotective and lower cytotoxic properties than other extracts.
\end{abstract}

Keywords: Guava (Psidium Guajava Linn.), Alcohol-Injured Cell, Hepatoprotective Properties, Clone 9 Cell, Cytotoxicity

\section{Introduction}

It is well established that alcohol consumption - both acute and chronic - adversely affects several host systems, including the nervous, cardiovascular, and immune systems. However, the most prominent changes are complications due to chronic exposure, such as alcoholic liver damage [1]. The liver is the primary organ for the metabolism, disposition and damage from ingested ethanol [2,3]. Alcohol consumptions produces a spectrum of histological abnormalities in the liver, including steatosis (fatty liver), steatohepatitis (alcoholic hepatitis), and cirrhosis [4].

Alcohol-induced liver diseases are the most common causes of chronic liver failure in the world. In 2004, $3.8 \%$ of all global deaths were attributable to alcohol and almost $50 \%$ of this was caused by cirrhosis of the liver. According to WHO statistics, the prevalence of cirrhosis of the liver in 2008 was about 0.8 million people in the world [5]. Because of several undesirable side effects of synthetic agents, there is growing focus to re-evaluate scientific basis of traditional herbal medicines that are claimed to possess hepatoprotective activity [6].

Guava (Psidium guajava Linn.), mainly grown in tropical and subtropical countries, is one of the major economic crops in Taiwan belong to family of Myrtaceae (Myrtaceae). Besides being consumed as fresh fruit, it can be processed into juices and jams and preserved products. In Taiwan, guava leaf is generally consumed as a hot water extraction in order to balance temperament, for blood clearance, and blood sugar reduction. Aside from these uses, Gutiérrez et al. [7] has reviewed the potential pharmacologic activities of the extract from the fruit, leaf, bark or roots; these activities include antioxidant, anti-allergy, anti-microbial, anti-genotoxic, antiplasmodial, cytotoxic, anti-spasmodic, cardioactive, cough supressant, anti-diabetic, anti-inflammatory and anti-no- 
ciceptive activities in vitro and/or in animal models. Previous studies mainly explore guava leaf extract related to diabetic treatments [8]. However, there is lack of scientific data regarding hepatoprotective activity of guava leaf on ethanol-induced hepatotoxicity, and it was consequently considered worthwhile to screen guava leaf for hepatoprotective activity on Clone 9 cells. These cells are a non-transformed cell line derived from normal rat liver [9]. This research was to investigate several guava leaf extracts hepatoxic effect on healthy clone 9 liver cells and its hepatoprotective effect on alcohol-induced heaptoxicity.

\section{Materials and Methods}

\subsection{Materials}

Clone 9 (ATCC number: CRL-1439) was obtained from Food Industry Research and Development Institute, fetal bovine serum (FBS) from Biological Industries, Israel, F-12K Nutrient mixture from GIBCO, Invitrogen, USA, Quick Cell Proliferation Assay Kit (wst-1) for from BioVision, USA, ALT-UV-IFCC kit (BC-0007 V3.0) from Formosa Biomedical Technology Corp., Taiwan, guava leaves were collected from Taiwan Guava Plantation and other chemicals used were analytical grade.

\subsection{Sample Preparations}

Extraction was done by using three different kinds of solvents; acetone, ethanol and water. Water extraction was done by two different temperatures; room temperature and $60^{\circ} \mathrm{C}$. Washed guava leaves were freeze dried and ground to powder. One gram guava leaf powder was mixed with $10 \mathrm{~mL}$ solvent and left to sit for 24 hours. The supernatant obtained was filtered (Whatman No.1), then evaporated by rotary evaporator at $40^{\circ} \mathrm{C}$ and dried by freeze dryer [10].

\subsection{Clone 9 Liver Cell Culture}

The experiments were performed in clone 9 cells, a hepatocyte cell line derived from normal mice. The cells were grown in F12K medium supplemented with $10 \%$ heatinactivated fetal bovine serum (FBS) and $1 \%$ penicillinstreptomycin. Culture incubation was done at $37^{\circ} \mathrm{C}$ with $5 \% \mathrm{CO}_{2}$. The cells were grown as monolayer and subcultures were performed with trypsinization using $0.05 \%$ trypsin in EDTA when cell growth reached confluence.

\subsection{Cell Viability Determination}

Cell viability was measured using a colorimetric assay for 96-well plates with 2-(4-iodophenyl)-3-(4-nitrophenyl)5-(2,4-disulfophenyl)-2H-tetrazolium (WST-1) reagent. Cells were added to 96-well plates in a concentration of 1 $\times 10^{5}$ cells $/ \mathrm{mL}$ and cultivated for 24 hour. For alcoholinduced injury model, clone 9 cells were treated with $1 \%$, $5 \%, 10 \%$ and $15 \%$ ethanol for 30 minutes and 60 minutes. Cell viability was measured with wst- 1 assay. For cytoxicity and hepatoprotective assay, clone 9 cells were treated with $20 \mu \mathrm{L}$ guava leaf extract $(50,100,200,400,500$, and $600 \mu \mathrm{g} / \mathrm{mL}$ ) and $180 \mu \mathrm{L}$ medium for 24 hours or guava leaf extract for 24 hours and alcohol for $30 \mathrm{mi}-$ nutes. To measured cell viability, the guava leaf ex- tract or ethanol (liquid phase in 96 well plate) were removed for ALT assay and $10 \mu \mathrm{L}$ of wst- 1 and $100 \mu \mathrm{L}$ of medium were added into cells and cells were incubated for an additional 2.5 hours. Absorbance was measured on ELISA plate reader (Epoch, BioTek Instruments, USA) with a test wavelength at $450 \mathrm{~nm}$. Cell viability (\%) was calculated by (cell number of sample group/cell number of control group) $\times 100 \%$.

\subsection{ALT Value Determination}

ALT (EC 2.6.1.2) was used as cell damage indicator. ALT was measured using commercially available reagent kit (BC-0007 V3.0, Formosa biomedical technology corp., Taiwan). For cytotoxic and hepatoprotective assay, after the cells were treated with guava leaf extract for 24 hours or ethanol for 30 minutes, $50 \mu \mathrm{L}$ of the solution was removed into new 96-well plate and $800 \mu \mathrm{L} \mathrm{R} 1$ reagent was added into these solutions. After incubation in $37^{\circ} \mathrm{C}$ for 5 minutes, $200 \mu \mathrm{L} \mathrm{R} 2$ reagent was added. Absorbance was measured in 340 and $405 \mathrm{~nm}(\mathrm{~A}=\mathrm{Abs}$ 405-Abs 340) as A1 and after one minute, the absorbance was measured again in the same wavelength as A2. ALT value was determined by $\operatorname{ALT}(\mathrm{U} / \mathrm{L})=(\mathrm{A} 1-\mathrm{A} 2) / \min \times 3376$.

\subsection{Statistical Analysis}

Every analysis was done in three replications and statistical analyses were done by using SPSS 13.0. Statistical analyses that conducted were analysis of variance (ANOVA) using Duncan's multiple range comparison post hoc with $p<0.05$ considered significant.

\section{Results and Discussion}

\subsection{Effect of Different Ethanol Concentrations and Exposure Times on Clone 9 Cell Viability}

After alcohol consumption, about $70 \%$ of alcohol will enter liver metabolism [10], and different cell lines will have different tolerance on alcohol concentration. This preliminary experiment was done to know optimum concentration and exposure time for ethanol-induced heaptotoxicity model on Clone 9 liver cells. 
Results that are shown in Figure 1 suggest that cell survival rate declines as the alcohol concentration increases. Cell viabilities of Clone 9 cells treated for 30 minutes exposure time and $1 \%, 5 \%, 10 \%$, and $15 \%$ of the ethanol concentrations were $107 \%, 79 \%, 37 \%$, and $11 \%$, and for 60 minutes were approximately 109\%, 78\%, 30\%, and $12 \%$, respectively. Hepatotoxicity caused by ethanol was dose-dependent, but different exposure times, 30 and 60 minutes, showed no apparent negative influence on cell viability. Therefore, for the purpose of the experiment $5 \%$ of the ethanol concentration with 30 minutes exposure time was used as alcohol induced liver cell injury model to analyze the protective effects of guava leaf extracts on alcohol induced liver injury on clone 9 .

The effects of ethanol have been suggested to be a result of the enhanced generation of oxy-free radicals during its oxidation in liver. The peroxidation of membrane lipids results in loss of membrane structure and integrity. The decrease in activity of antioxidant enzymes superoxide dismutase, glutathione peroxidase are speculated to be due to the damaging effects of free radicals produced following ethanol exposure or alternatively could be due to a direct effect of acetaldehyde, formed by oxidation of ethanol [11].

\subsection{Effect of Different Guava Leaf's Extract on Clone 9 Cell Viability and ALT (Cytotoxicity Assay)}

Cytotoxicity assay was done to observe different guava leaf extract effect on healthy Clone 9 cell, to determine whether or not it can cause significant damage in healthy cells. After being cultured for 24 hours, ethanol and acetone extracts in high concentrations showed cytotoxic effects on clone 9 liver cells which is shown as reduced

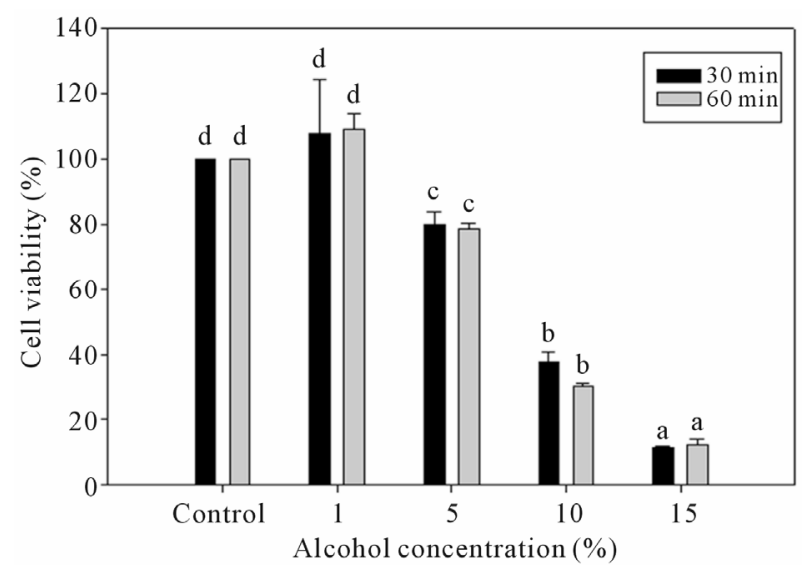

Figure 1. Effect of various concentrations of alcohol on cell viability of clone 9 after (A) 30 minutes and (B) 60 minutes incubation by wst-1 assay. ${ }^{\mathrm{a}-\mathrm{d}}$ Data with different superscripts are significantly different at $P<0.05$. cell viability by wst-1 assay (Figure 2). Water extract of guava leaves in $500 \mu \mathrm{g} / \mathrm{mL}$ concentration resulted in cell survival rate about $94 \%$, and no toxicity occured at concentration of $500 \mu \mathrm{g} / \mathrm{mL}$ or lower, significantly. However, the cell that was treated with $400 \mu \mathrm{g} / \mathrm{mL}$ and $200 \mu \mathrm{g} / \mathrm{mL}$ hot water extracts has cell viability about $92 \%$ and $96 \%$, but no significant toxicity occur on clone 9 liver cell in concentration of $400 \mu \mathrm{g} / \mathrm{mL}$ or lower.

Aside from the cell viability assay, this experiment also measured ALT value. When certain types of cells are damaged, they may effuse enzyme into the blood and alanin aminotransferase (ALT) is one of these enzymes; this indicates cell damage [12]. The upper range of normal in the present study was taken as less than $40 \mathrm{U}$, because this value is widely used by many clinicians as the upper normal [13]. ALT values from four different solvent extractions of the guava leaf extract were shown in Figure 3. Results shows that ALT increases extract concentrations increase, this can also be referred to as dosedependent cell damage caused by guava extracts on clone 9 liver cells. Cells that were treated by acetone extract at $200 \mu \mathrm{g} / \mathrm{mL}$ or below and ethanol extract at $500 \mu \mathrm{g} / \mathrm{mL}$ or below shows ALT value within normal range, while in the water and hot water extracts of guava leaves, transglutaminase enzyme activity (ALT) did not increase or exceed normal level.

\subsection{Effect of Different Guava Leaf's Extract on Alcohol-Injured Clone 9 Cell Viability and ALT (Hepatoprotective Assay)}

This experiment aims to observe pre-protective effect of the different extraction of guava leaf extract for the alcohol-induced liver injury. The experiment was done by treated clone 9 liver cell with guava leaf extract for 24 hours, then $5 \%$ ethanol was added for 30 minutes to induce injury thereafter cell viability was measured. The survival rate of $5 \%$ alcohol induced injury on clone 9 liver cells was about $79 \%$ with ALT value and this result was used as the control group.

In this study, it was seen that administration of guava leaf extracts on ethanol-induced hepatotoxicity has potential as hepatoprotective agent in lower concentrations. Higher hepatoprotective effects were revealed by ethanol and hot water extracts. However, in high concentrations, cell viability of ethanol extract tends to decrease. These findings may be due to the cytotoxic ability of these guava leaf extracts, specifically acetone and ethanol extracts (Figure 4). The maximum protection against ethanol-induced hepatic aberrations was achieved by hot water extract.

Hot water extract of guava leaf can be considered to be an effective hepatoprotective herbal as it ameliorated the 

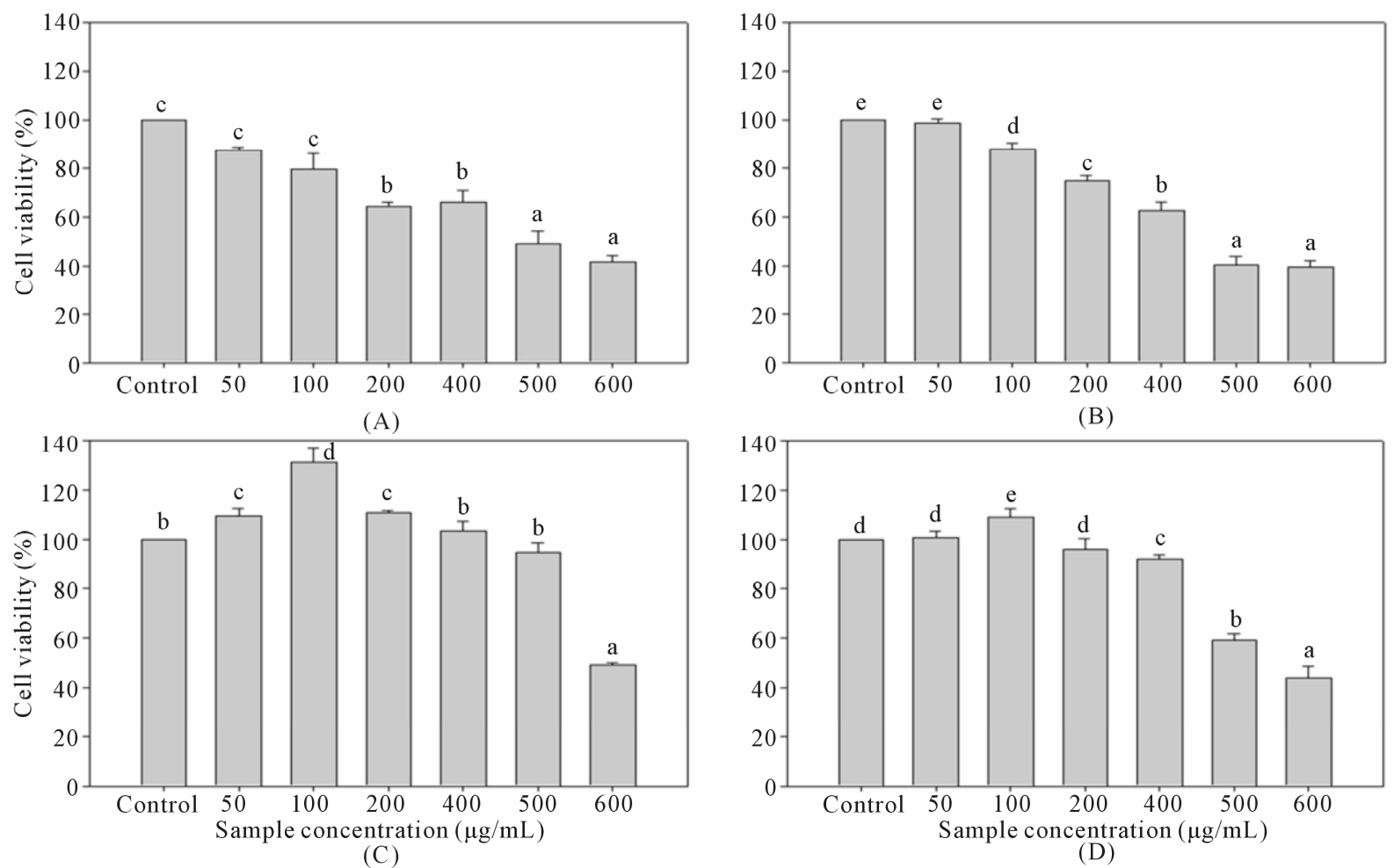

Figure 2. Effect of various concentrations of guava leaf (A) acetone, (B) ethanol, (C) water, and (D) $60^{\circ} \mathrm{C}$ water extract on cell viability of clone 9 by wst-1 assay (toxicity assay). ${ }^{a-e}$ Data with different superscripts are significantly different at $P<0.05$.
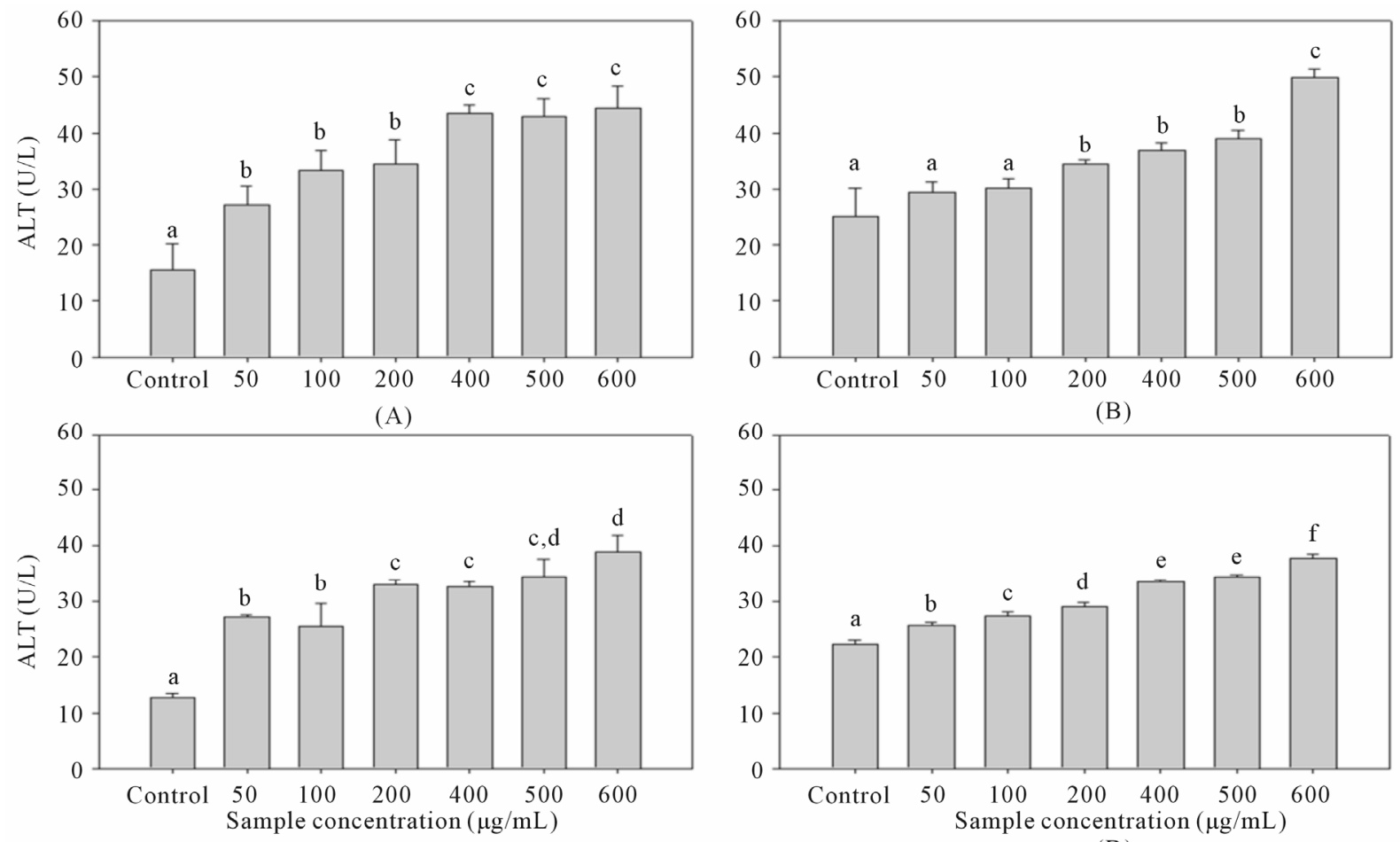

(C)

(D)

Figure 3. Effect of various concentrations of guava leaf (A) acetone, (B) ethanol, (C) water, and (D) $60^{\circ} \mathrm{C}$ water extract on ALT of clone 9 by wst-1 assay. ${ }^{\text {a-f }}$ Data with different superscripts are significantly different at $P<0.05$. 

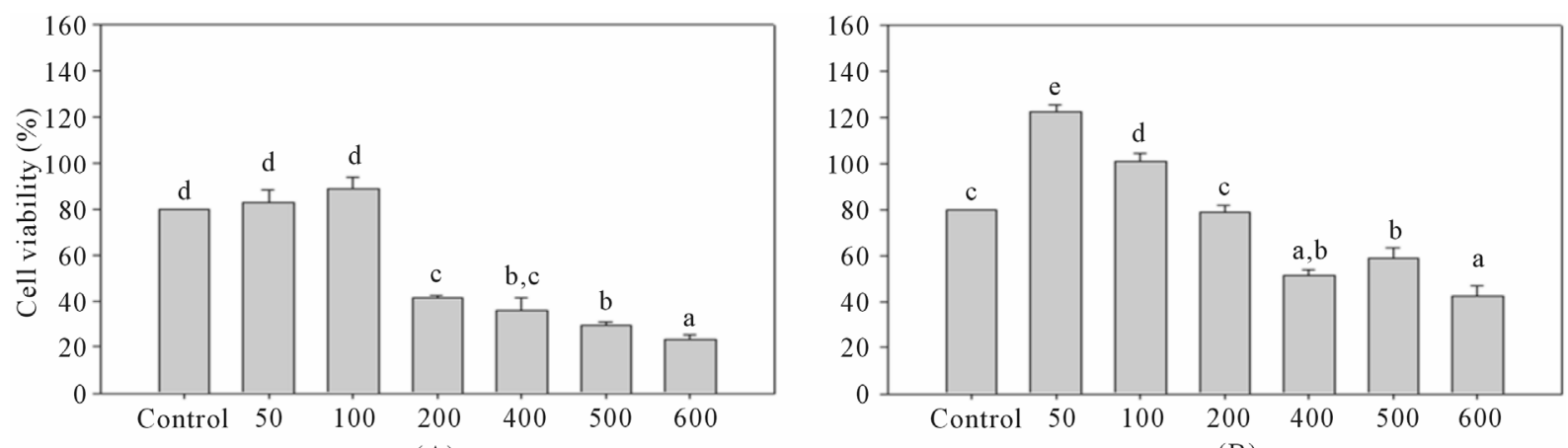

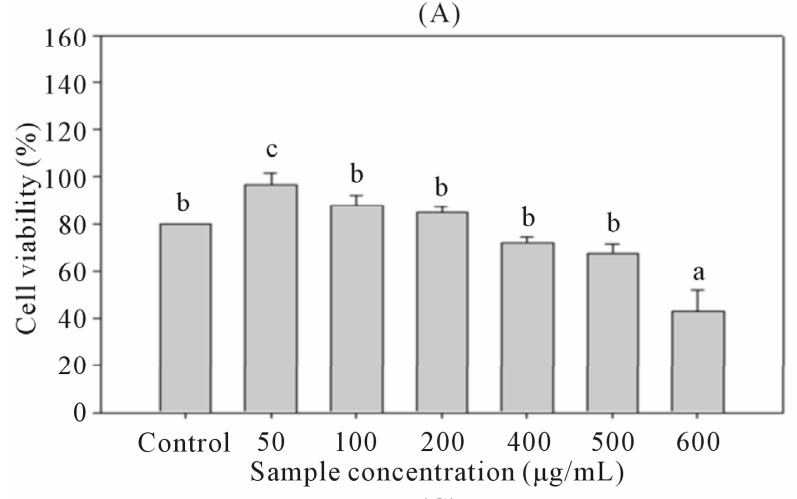

(C)

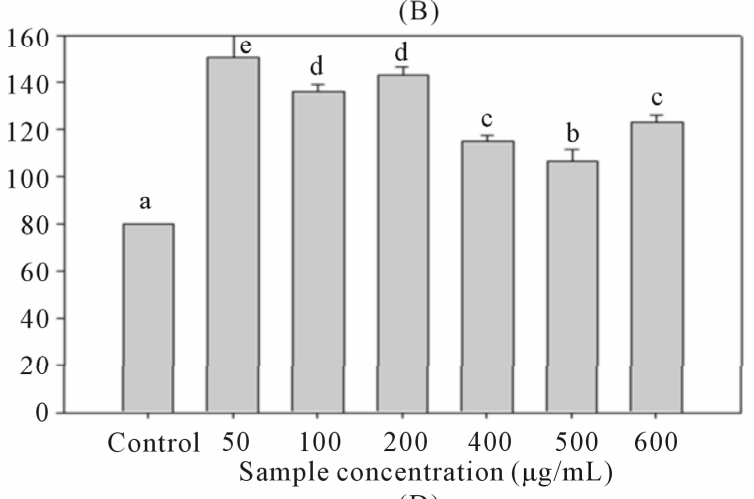

(D)

Figure 4. Effect of various concentrations of guava leaf (A) acetone, (B) ethanol, (C) water, and (D) $60^{\circ} \mathrm{C}$ water extracts on cell viability of clone 9 after 24 hours incubation and $5 \%$ alcohol-induced for 30 minutes by wst-1 assay. ${ }^{\text {a-e }}$ Data with different superscripts are significantly different at $P<0.05$.

damage cause by ethanol and lower cytotoxicity effect. The probable mechanism of guava leaf protective action against ethanol-induced hepatocellular metabolic alterations could be by its antioxidant properties, which may neutralize the effect of ethanol. Boiled water extract of guava leaf possess strong antioxidant properties especially in free radical-scavenging due to its high content of feluric and gallic acid [14]. In addition, concentration when administering of guava leaf extract must also considered since cytotoxic effect can be deleterious to cells in high concentrations.

\section{Conclusions}

Ethanol and acetone extracts at low concentrations 100 $\mu \mathrm{g} / \mathrm{mL}$ and $50 \mu \mathrm{g} / \mathrm{mL}$ has no effect on cell growth, but tend to have cytototoxicity effect at higher concentrations. Water and hot water extracts in concentration of 500 $\mu \mathrm{g} / \mathrm{mL}$ or below have no cytotoxic effects on clone 9 liver cells. Cells that were treated by acetone extracts at $200 \mu \mathrm{g} / \mathrm{mL}$ or lower and ethanol extracts at $500 \mu \mathrm{g} / \mathrm{mL}$ or lower showed ALT value within normal range, while in the water and hot water extracts, ALT value did not increase or exceed normal level in all concentrations.

By using 5\% alcohol concentration for 30 minutes as alcohol-induced injury model, the hepatoprotective pro- perties of guava (Psidium guajava Linn.) extracts on alcohol-induced liver cell injury was significant in concentration of $100 \mu \mathrm{g} / \mathrm{mL}$ or lower for ethanol and all concentration for hot water extracts. Higher concentration of ethanol showed decrease in cell viability. However, the protection offered by hot water extract seems relatively greater than other extracts due to higher heaptoprotective and lower cytotoxic effects. High concentrations of guava leaf extract inevitably induces cytotoxic effects, therefore, careful administration is advised.

\section{REFERENCES}

[1] K. A. N. Messingham, D. E. Faunce and E. J. Kovacs, "Alcohol, Injury, and Cellular Immunity," Alcohol, Vol. 28, No. 3, 2002, pp. 137-149. doi:10.1016/S0741-8329(02)00278-1

[2] C. S. Lieber, "Alcoholic Fatty Liver: Its Pathogenesis and Mechanism of Progression to Inflammation and Fibrosis," Alcohol, Vol. 34, No. 1, 2004, pp. 9-19. doi:10.1016/j.alcohol.2004.07.008

[3] S. Ramaiah, C. Rivera, and G. Arteel, "Early-Phase Alcoholic Liver Disease: An Update on Animal Models, Pathology, and Pathogenesis," International Journal of Toxicology, Vol. 23, No. 4, 2004, pp. 217-231. doi:10.1080/10915810490502069 
[4] R. N. M. MacSween and A. D. Burt, "Histologic Spectrum of Alcoholic Liver Disease," Seminars Liver Disease, Vol. 6, No. 3, 1986, pp. 221-232. doi:10.1055/s-2008-1040605

[5] World Health Organization, "Causes of Death 2008: Data Sources and Methods," World Health Organization, Geneva, 2010.

http://www.who.int/healthinfo/global burden disease/co d_2008_sources_methods.pdf

[6] S. Shahani, "Evaluation of Hepatoprotective Efficacy of APCL-A Polyherbal Formulation in Vivo in Rats," Indian Drugs, Vol. 36, 1999, pp. 628-631.

[7] R. M. Gutiérrez, S. Mitchell and R. V. Solis, "Psidium Guajava: A Review of Its Traditional Uses, Phytochemistry and Pharmacology," Journal of Ethnopharmacology, Vol. 117, No. 1, 2008, pp. 1-27. doi:10.1016/j.jep.2008.01.025

[8] Y. Deguchi and K. Miyazaki, "Anti-Hyperglycemic and Anti-Hyperlipidemic Effects of Guava Leaf Extract," Nutrition and Metabolism, Vol. 7, No. 1, 2010, pp. 1-9.

[9] I. B. Weinstein, N. Yamaguchi, J. M. Orenstein, R. Gebert and M. E. Kaighn, "Gene Expression and Carcinogenesis in Cultured Liver," In: L. E. Gerschenson and
E. B. Thompson, Eds., Academic Press, New York, 1975, pp. 441-459.

[10] N. J. Wu, "Hypoglycemic Effect of Guava (Psidium guajava Linn.) Leaf Extracts in Streptozotocin-Nicotinamide Induced Type 2 Diabetic Rat," Ph.D. Thesis, National Taiwan University, Taipei, 2007.

[11] R. Sandhir and K. D. Gill, "Hepatoprotective Effects of Liv-52 on Ethanol Induced Liver Damage in Rats," Indian Journal of Experimental Biology, Vol. 37, 1999, pp. 762-766.

[12] D. S. Pratt and M. M. Kaplan, "Evaluation of Abnormal Liver-Enzyme Result in Asymptomatic Patients," The New England Journal of Medicine, Vol. 342, 2000, pp. 1266-1271. doi:10.1056/NEJM200004273421707

[13] L. V. Crowley, "The Reitman-Frankel Colorimetric Transminase Produced in Suspected Myocardial Infarction," St. Mary's Hospital, Minnesota, 1967.

[14] H. Y. Chen and G. C. Yen., "Antioxidant Activity and Free Radical-Scavenging Capacity of Extracts from Guava (Psidium guajava L.) Leaves," Food Chemistry, Vol. 101, No. 2, 2006, pp. 686-694. doi:10.1016/j.foodchem.2006.02.047 